\title{
COMMUNITY PARTICIPATION IN NATURAL RESOURCE MANAGEMENT IN SRI LANKA - A REVIEW OF SOME PROJECTS
}

\author{
D M S H K Ranasinghe \\ Department of Forestry \& Environmental Science \\ University of Sri Jayewardenepura \\ Nugegoda.
}

Community participation is an approach that is receiving attention across the globe, and one that marks a departure from the 'catching up' , 'top down' orientation which characterised the cultural dimension of the modernist perspective of development which was in vogue in the 1960's.

This paper reviews a number of community participation projects which trad been formulated to conserve the country's natural resources and to empower people and rural communities to manage and protect them in a sustainable manner while reaping economic benefits. The projects that are discussed are two coastal resources management projects of the Coast Conservation Department located in Hikkaduwa (dealing with the conservation of corel reef) and Rekawa (dealing with lagoon and mangrove habitat conservation) and two community based management projects located in Ritigala (dealing with medicinal plants) and Kahalle - Pallekelle (dealing with human-elephant conflict). The following aspects are highlighted in each of these projects/cases;

* the degree/level of community participation

* the presence of collaborative decision making and co-management

* the key natural resource problems and their underlying causes

* the key stakeholders and interest of each stakeholder group

* the management strategies adopted, the extent to which these have been able to address the needs of the community

* the degree of sustainability

The paper synthesises the degree of success and failures of each project in its approach to the community, planning, implementation and monitoring. Recommendations are given for future improvement of community based conservation in Sri Lanka.

Proceedings of the Third Annual Forestry Symposium 1997 of the Department of Forestry and Environmental Science, University of Sri Jayewardenepura, Sri Lanka 